\title{
Technical and Scale Efficiencies for Chinese Rural Credit Cooperatives: A Bootstrapping Approach in Data Envelopment Analysis
}

\author{
Fengxia Dong and Allen Featherstone
}

Working Paper 04-WP 366

July 2004

\author{
Center for Agricultural and Rural Development \\ lowa State University \\ Ames, lowa 50011-1070 \\ www.card.iastate.edu
}

Fengxia Dong is an associate scientist in the Center for Agricultural and Rural Development at lowa State University. Allen Featherstone is a professor in the Department of Agricultural Economics at Kansas State University.

This publication is available online on the CARD Web site: www.card.iastate.edu. Permission is granted to reproduce this information with appropriate attribution to the authors.

For questions or comments about the contents of this paper, please contact Fengxia Dong, 571 Heady Hall, lowa State University, Ames, IA 50011-1070; Ph: 515-294-0470; Fax: 515-2946336; E-mail: fdong@iastate.edu.

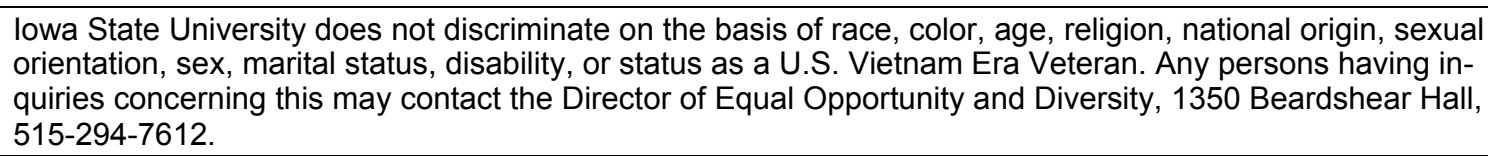
orientation, sex, marital status, disability, or status as a U.S. Vietnam Era Veteran. Any persons having inquiries concerning this may contact the Director of Equal Opportunity and Diversity, 1350 Beardshear Hall, 515-294-7612. 


\begin{abstract}
Chinese rural credit cooperatives (RCCs) are a major supplier of credit to the rural sector in the country. However, Chinese RCCs are currently encountering operating problems, and an experimental reform is being carried out to restructure and reform the RCCs. In order to have some idea about the efficacy of reform, it is important to have an understanding of the institutional economics underlying the delivery of rural credit in China. This paper evaluates pure technical efficiency, overall technical efficiency, and scale efficiencies for RCCs in China using nonparametric techniques. The use of a bootstrap algorithm is proposed to perform inference for efficiency measures.
\end{abstract}

Keywords: bootstrapping, Chinese rural credit cooperatives, data envelopment analysis, scale efficiency, technical efficiency. 


\title{
TECHNICAL AND SCALE EFFICIENCIES FOR CHINESE RURAL CREDIT COOPERATIVES: A BOOTSTRAPPING APPROACH IN DATA ENVELOPE ANALYSIS MODELS
}

\begin{abstract}
Introduction
Like many developing countries, small enterprises and farmers in China suffer from a lack of access to capital. It is difficult for them to get credit from banks. In China, there are over 800 million rural inhabitants who engage in farming, forestry, fishery, and husbandry; and there are over 20 million township and village enterprises (TVEs), which account for about 30 percent of gross domestic product and play an important part in the growth of the national economy. Although there are many commercial banks in China, most of them do not operate in the below-county-level areas because of operational cost, high financial risk, and low return. Since 1998, the four state banks (Agriculture Bank, Bank of China, Construction Bank, and Industrial and Commercial Bank) have withdrawn or merged 10,728 branches in five provinces, and most of these branches are in rural areas (Mu 2003). Moreover, the decision-making power of the four state banks' branches that are at or below the county level to grant credit is reduced. The rural sector is supposed to be served mainly by a state bank (Agricultural Bank of China) (which is reducing its countryside branches), a policy bank (Agricultural Development Bank of China), and thousands of rural credit cooperatives (RCCs). However, Agricultural Bank's support to agriculture has been decreasing since its allocation of resources expanded to cities and industries in the mid-1990s. Subsequently, its agricultural loans decreased from 98 percent before the mid-1980s to a current 10 percent of total loans (Han n.d.), and RCCs are now the main force for serving peasants and TVEs. By the end of June 2003, there were 34,909 RCCs with 628,000 employees located at the township level, and RCCs had 2.2 trillion yuan of deposits and 1.6 trillion yuan of loans, which accounted for about 12 percent of total deposits and 11 percent of total loans by all financial organizations in China, respectively. In sharp contrast, RCCs had 696.6 billion yuan of
\end{abstract}


agricultural loans, which accounted for about 84 percent of total agricultural loans from all financial organizations (Mu 2003).

Since their initiation in the early 1950s to combat usury, RCCs had been the core of the rural financial system and played an important role in mobilizing rural household savings, channeling a significant share into loans made to TVEs, and funneling capital to agricultural and other development projects in rural areas. The RCCs in China are not "cooperative" financial institutions by nature. According to a definition of the International Labor Organization in 1994, a cooperative is a voluntarily organized and democratically managed organization. The "Management Rules of Rural Credit Cooperatives in China in 1997" defines the credit cooperative as an organization in which members could voluntarily buy shares, implement democratic management, and share risks and benefits. However, China's RCCs have never met those standards. The members, who join mostly under administrative forces, have never managed business organizations and have no freedom to withdraw membership (Xie 2001). Before 1996, RCCs were managed by the Agricultural Bank of China and only afterwards were they restructured as a separate set of independent institutions. However, the RCCs are still partly under the control of the local governments, which tend to increase the supply of capital to agricultural production with little attention to institutional sustainability. In addition, because of low economic returns to most farmers and TVEs, the fragile agricultural economy, a narrow range of products, and bad credit or ethical risks of some borrowers, RCCs' operational risk is very high. Because of the control and interference of local governments and local branches of the state banks, an abundance of "crony capitalism" (i.e., implied and overt connections between regulation and corruption, both bureaucratic and political), high financial risks as well as problems in selfoperation and management, poor service, and low quality of employees, the RCCs have a severe problem with non-performing loans. By the end of 1996, the non-performing loans amounted to about 238 billion yuan, accounting for 38 percent of the total loans. ${ }^{1}$ In addition, 53 percent of the RCCs had a deficit (Zuo 2001). Accordingly, the People's Bank of China, the central bank, reported that the RCCs had a combined negative net worth.

With severe problems in RCCs, which are currently the major financial institutions providing capital to farmers, farmers cannot obtain necessary capital and they have to use people-to-people private loans. As shown in Figure 1, between 1995 and 1999, people-to- 


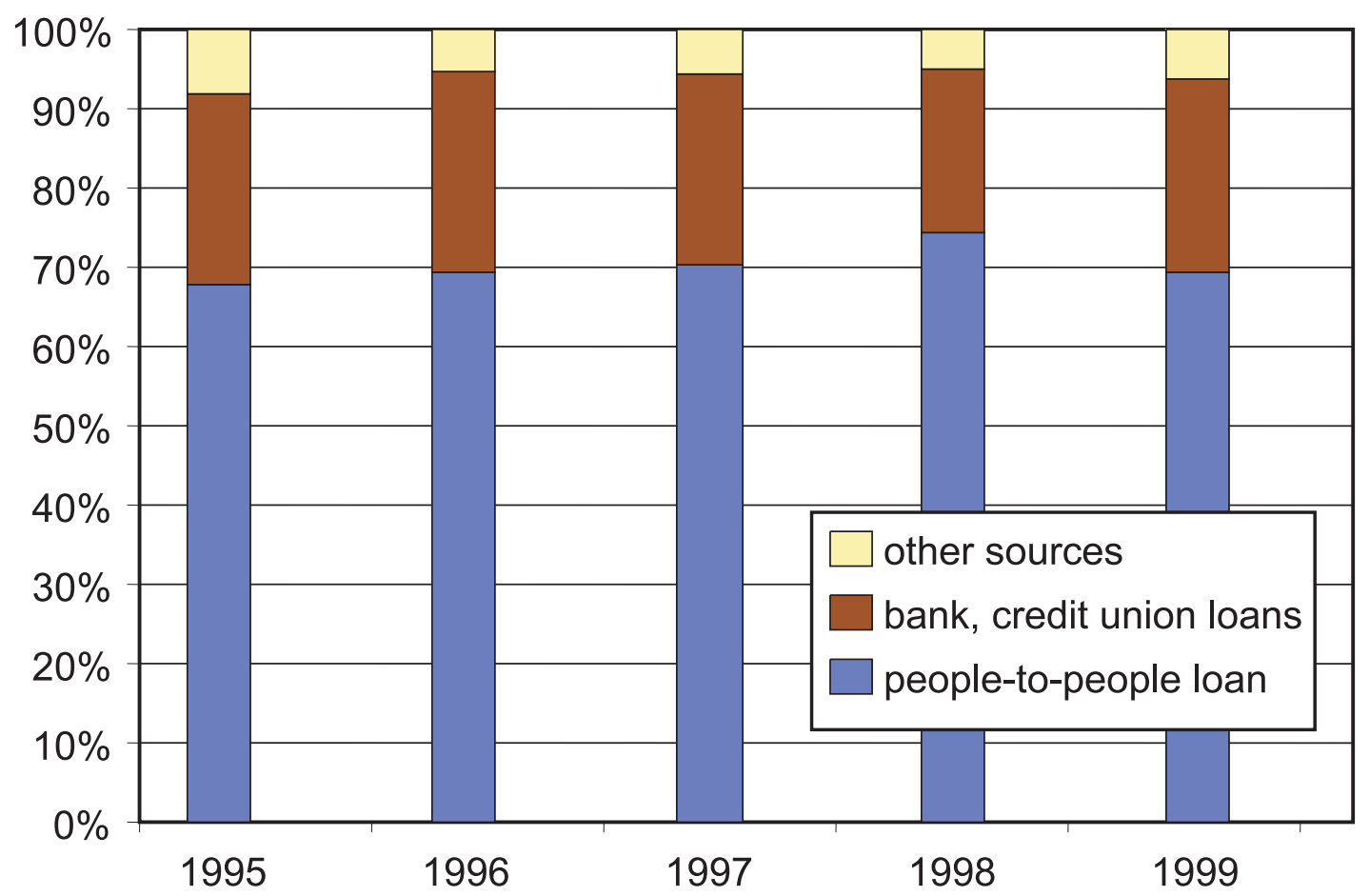

FIGURE 1. Sources of farmers' loans, 1995-1999

people loans accounted for about 70 percent of farmers' total loans (Wen 2001). Over 40 percent of farmers' total loans are needed for production, as illustrated in Figure 2. Compared to the 1980s, when most loans came from the Agricultural Bank of China and RCCs, and compared to the period between 1990 and 1994, when 40 percent of loans came from the Agricultural Bank of China and RCCs, farmers' loans from financial institutions decreased to below 25 percent between 1995 and 1999 (Wen 2001). Given limitations and potential problems existing in people-to-people loans, such as their small scale, higher interest rate or usury, and disputation, people-to-people loans cannot effectively satisfy farmers' capital requirements. Scarcity of agricultural capital is restricting China's agricultural development (Han 2003). Therefore, improvement in RCCs' capacity for channeling capital into agriculture is of crucial importance.

Consequently, RCCs are experiencing reform and reconstruction. The first reform was introduced following the separation of RCCs from the Agricultural Bank of China. This reform introduced a microloan scheme supported by agricultural lending from the People's Bank of China. Although this reform improved access by rural households to RCC loans, some other problems were incurred, such as having more microloans and consequently 


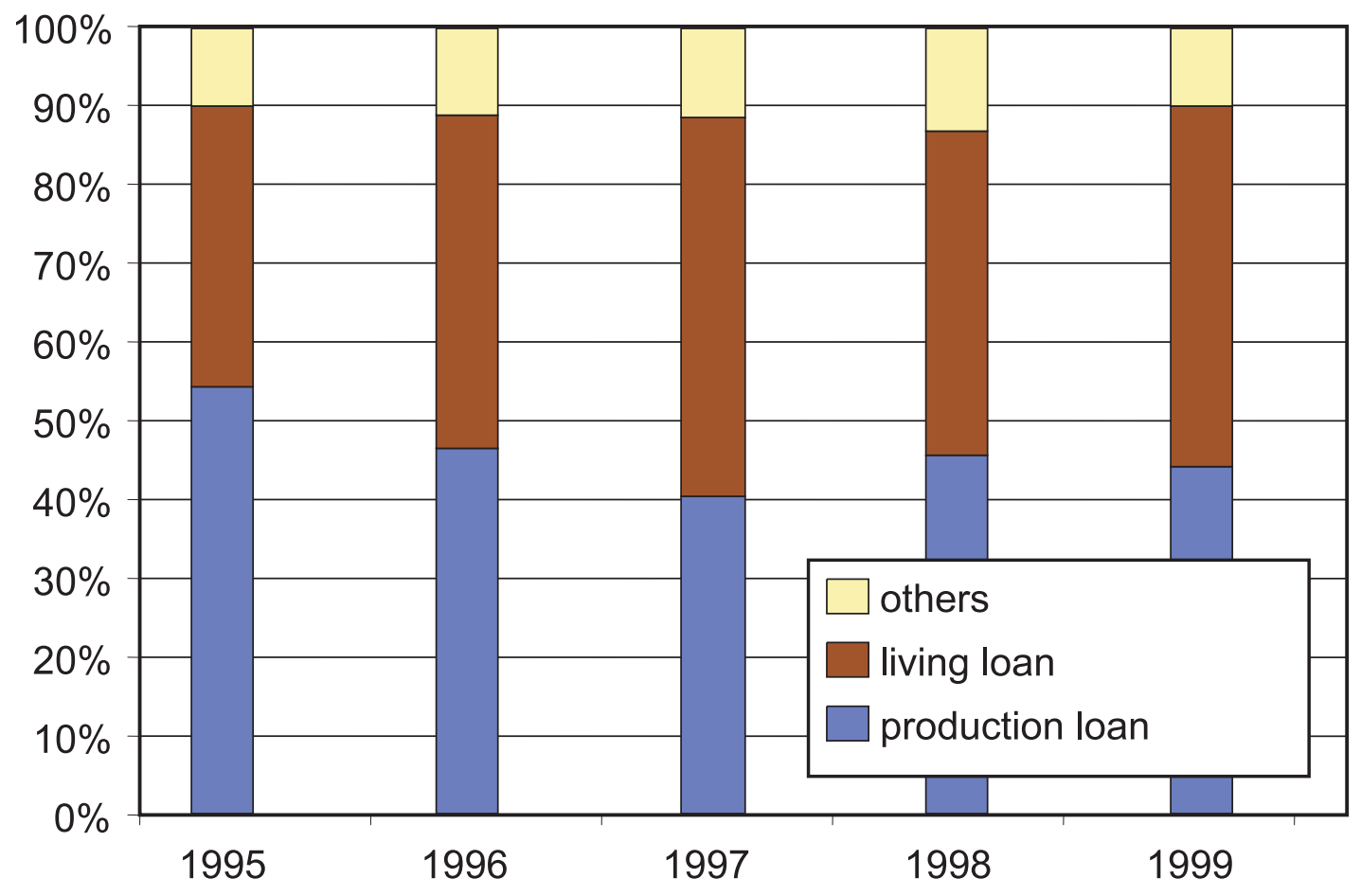

FiguRe 2. Purposes of farmers' loans, 1995-1999

greater financial losses (Xie 2003). In August 2003, the State Council of China issued an instrument for experimental reform of RCCs. The experimental reform will be carried out in seven provinces, Zhejiang, Shandong, Jiangxi, Guizhou, Jilin, Shaanxi, and Jiangsu, and one city, Chongqing, in 2004 (Jiangsu has been undertaking reform since it was chosen as the experimental province in 2000 and will continuously deepen its reform). The reform and reconstruction focus on two issues. One is to reform the structure of and clarify RCCs' ownership or property rights. Given different conditions and development levels of areas RCCs reside in, there are three choices for the organization patterns of RCCs: the first is to reconstruct RCCs as shareholding financial institutions such as commercial banks or cooperative banks; the second is to combine RCCs and county credit unions as a united entity instead of separate legal entities; and the third is to keep the current structure in which each RCC or county credit union is an independent legal entity and to improve the cooperative system. In addition, RCCs with high risk or debt or that reside in urban or suburban areas and provide little service to agriculture can be merged, restructured, or even revoked. The second critical issue is the reform of the RCCs' management system. RCCs will be moved under the admini- 
stration of provincial governments, and the China Banking Regulatory Commission will supervise their operation.

To restructure and reform RCCs, it is necessary to understand their technical and scale efficiencies. Greater degrees of efficiency among RCCs could result in greater accessibility of loan funds, higher profitability, increased services for farmers, and greater probability for long-term viability by using savings-generated efficiencies (Ellinger 1994). Efficiencies in China's RCCs may not exist for several reasons. First, under the management and intervention of state banks and local governments, along with abundance of "crony capitalism," the RCCs' performance is undermined. Moreover, because of political and social concerns, bankruptcy or other market mechanisms for improved performance do not exist. Second, poor means and technology of services, low professional skill levels of employees, and redundant personnel increase the operational costs and decrease efficiencies. There were over 620,000 employees working for the RCCs, with average per capita assets of 21,900 yuan and average per capita costs as high as 42,000 yuan in 1999 (Xie 2001). In addition, the Chinese economy is characterized by high savings, inefficient financial intermediaries, and underutilization of economic resources (Fang 2001). RCCs, as one microsector of the financial economy, are unable to avoid such problems. If the RCCs become more efficient, then improved profitability, greater amounts of intermediated funds, and better service quality for rural customers are expected.

Given the problems experienced by RCCs and increased pressures on RCCs' reform and reconstruction, surprisingly, to the authors' knowledge, no empirical research on efficiencies of China's RCCs has been undertaken. In contrast, a large number of studies on efficiency of financial institutions, especially in the United States, have been undertaken. For example, Berger and Humphrey (1997) list 122 frontier studies that apply to efficiency analysis of depository financial institutions. Among those listed, studies on U.S. financial institutions accounted for 66 of the 116 single-country studies.

To fill this gap, the purpose of this paper is to analyze the technical and scale efficiency and the nature of returns to scale (i.e., increasing, constant, or decreasing returns) in China's RCCs. In addition, in order to determine the statistical precision of the estimated efficiency scores, we construct confidence intervals for the efficiency 
scores produced by the linear programming approach by using bootstrapping techniques. Viewed in this context, the empirical results presented in this paper provide extremely important insights into efficiencies in RCCs in China and the basis for research on restructuring of RCCs and relevant regulations. The precise nature of efficiency scores in RCCs is extremely important, both from an academic and policy perspective.

In the remaining sections we introduce the methodology used in this study, discuss data issues, analyze the empirical results, and summarize our findings.

\section{Methodology}

\section{Nonparametric Method}

Empirical studies have used either duality theory with the estimation of cost functions or nonparametric estimation methods to evaluate efficiency in the financial services industry (Featherstone and Moss 1994). The parametric method can capture and isolate statistical noise present in the data. However, the need to impose an assumed functional form for the underlying technology and an assumed distribution for the inefficiency term make the parametric method less flexible. The nonparametric method seems attractive without imposing a specific functional form for the technology as well as the distributional assumption for the inefficiency term. The nonparametric method is often referred to as data envelopment analysis (DEA). DEA involves the utilization of mathematical programming techniques to construct a bestperformance benchmark from the observed data on inputs and outputs. The constructed relative efficiency frontiers are non-statistical or non-parametric in the sense that they are constructed through the envelopment of the decision-making units (DMUs), with the best-performance DMUs forming the frontier. Within this methodological framework, the overall technical efficiency is decomposed into pure technical and scale efficiencies, a method initially suggested by Farrell (1957) and later extended by Banker, Charnes, and Cooper (1984), and Färe, Grosskopf, and Lovell (1985). Empirical applications of the decomposition of overall technical efficiency to banking include but are not limited to those by Rangan et al. (1988), Aly et al. (1990), and Drake and Hall (2003). 
Pure technical efficiency is a measurement of how far off a DMU is from the production frontier. It indicates the potential reduction in inputs a DMU can achieve by adopting the best production and/or management practices of the best-performance DMU. Scale efficiency indicates whether the DMU is producing at the most efficient size. It measures the proportional reduction in input usage that is achieved if the DMU is operating at constant returns to scale. Overall technical efficiency is the combined effects from both pure technical efficiency and scale efficiency.

A DMU's efficiency is a relative measure. It compares a DMU's performance to the best performance implicit in the observed input-output combinations. Measuring performance against best practice, DMUs can identify and then improve their less-efficient practices. When there are many DMUs each producing multiple outputs from multiple inputs included in a DEA analysis, the benchmark of a DMU will be made up of more than one DMU unless the DMU has the best performance in producing all outputs. A DMU will not usually have the best performance in producing all outputs and consequently the best-performance benchmark of a DMU may include a number of DMUs that have the best performance in producing one or more outputs.

Subsequent to the analysis is the mathematical linear programming approach for estimating technical and scale efficiency. Consider the situation with $\mathrm{k}$ firms or DMUs, each producing $m$ outputs $\mathrm{Y}\left(=\left[\mathrm{Y}_{1}, \ldots, \mathrm{Y}_{\mathrm{k}}\right]\right)$ by using $\mathrm{n}$ inputs $\mathrm{X}\left(=\left[\mathrm{X}_{1}, \ldots, \mathrm{X}_{\mathrm{k}}\right]\right)$, where $\mathrm{Y}_{\mathrm{i}}$ $(i=1, \ldots, k)$ is the $(m \times 1)$ vector of outputs and $X_{i}$ is the $(n \times 1)$ vector of inputs. The input requirement set, or reference technology, can then be represented by the free disposal convex hull of the observations. The smallest convex set contains the observations with the least input requirement set for the certain level of outputs. For each DMU, i, pure technical efficiency, is calculated by solving the problem of finding the lowest multiplier $\lambda_{\mathrm{i}}$, which must be applied to the use of inputs by $i$ to ensure it is still a member of the reference technology. The pure technical efficiency is obtained by solving the following DEA model: 
$\operatorname{Min} \lambda_{\mathrm{i}}$

subject to :

$$
\begin{gathered}
x_{11} z_{1}+x_{12} z_{2}+\ldots+x_{1 k} z_{k} \leq \lambda_{i} x_{1 i} \\
x_{21} z_{1}+x_{22} z_{2}+\ldots+x_{2 k} z_{k} \leq \lambda_{i} x_{2 i} \\
\ldots \ldots \\
x_{n 1} z_{1}+x_{n 2} z_{2}+\ldots+x_{n k} z_{k} \leq \lambda_{i} x_{n i} \\
y_{11} z_{1}+y_{12} z_{2}+\ldots+y_{1 k} z_{k}-y_{1 i} \geq 0 \\
y_{21} z_{1}+y_{22} z_{2}+\ldots+y_{2 k} z_{k}-y_{2 i} \geq 0 \\
\ldots \ldots \\
y_{m 1} z_{1}+y_{m 2} z_{2}+\ldots+y_{m k} z_{k}-y_{m i} \geq 0 \\
z_{1}+z_{2}+\ldots+z_{k}=1
\end{gathered}
$$

where $z$ is an intensity vector and each $z_{i}(i=1, \ldots, \mathrm{k})$ is positive; $x_{i j}(i=1, \ldots, \mathrm{n} ; j=1, \ldots, \mathrm{k})$ is the $i$ th input used by the $j$ th DMU; and $y_{i j}(i=1, \ldots, \mathrm{m} ; j=1, \ldots, \mathrm{k})$ is the $i$ th output produced by the $j$ th DMU. The symbol $\lambda_{\mathrm{i}}(i=1, \ldots, \mathrm{k})$ is the measure of pure technical efficiency for the $i$ th DMU. To determine overall technical efficiency (labeled $\theta_{\mathrm{i}}$ ), the DEA model in equation (1) is solved without the constraint that the sum of $z_{i}$ is 1 , implying that the input set is convex and the technology is variable returns to scale (VRS). The measure of scale efficiency $\left(S_{\mathrm{i}}\right)$ is the ratio of overall technical efficiency and pure technical efficiency $\left(\theta_{\mathrm{i}} / \lambda_{\mathrm{i}}\right)$. If $S_{\mathrm{i}}$ is equal to 1 , then the DMU is scale efficient; if $S_{\mathrm{i}}$ is less than 1 , then the DMU is inefficient. To determine the source of scale inefficiency when $S_{\mathrm{i}} \neq 1$, the DEA model in equation (1) needs to be estimated by replacing the constraint that the sum of $z_{\mathrm{i}}$ is 1 with the constraint that the sum of $z_{\mathrm{i}}$ is less than or equal to 1 ; that is, the technology is non-increasing returns to scale (NIRS). Then if the objective function of the DEA model under NIRS (labeled $\gamma_{\mathrm{i}}$ ) is equal to pure technical efficiency $\left(\lambda_{\mathrm{i}}\right)$, decreasing returns to scale exist; otherwise, increasing returns to scale exist (Färe, Grosskopf, and Lovell 1985, p. 184).

RCCs allocate resources and control internal processes by managing their resources, facilities, and employees. RCCs that do this best are best performers and are on the efficient frontier. RCCs can employ the DEA results to benchmark their processes and find potential areas for improvement. 
Technical and Scale Efficiencies for Chinese Rural Credit Cooperatives / 9

\section{Bootstrapping}

DEA methods have been widely applied, as described earlier. Yet most researchers have ignored the sampling noise in the resulting efficiency estimators. Typical DEA applications have no or only slight measurement and discussion of uncertainty surrounding efficiency estimates. The results assume that any deviation from the frontier production function is attributable to technical inefficiency. However, uncertainty is present in the DEA methods through sampling variability or the uncertainty arising from the estimation of the frontier. The ignorance of these statistical properties and uncertainty can lead to biased DEA estimates of efficiency and consequently to misleading conclusions.

Because of the complexity of DEA estimators, in the general multi-output and multiinput case, bootstrapping is currently the only way to investigate sampling properties of DEA estimators and to calculate confidence intervals (Simar and Wilson 1998). Bootstrapping is based on the idea that if the data are viewed as a set of random draws from an underlying population, random draws from the sample are also random draws from the same population. How well the data-generating process (DGP) characterizes the true data generation and how well the DGP is mimicked in the resampling simulation directly affect the performance of the bootstrap in terms of the validity of the conducted statistical inference (Löthgren and Tambour 1999). Assumptions on the DGP comprise the statistical model. Simar and Wilson propose the bootstrap for DEA with the assumption that the distribution of efficiency scores is independently distributed.

Subsequent developments have extended the bootstrapping approach. In DGP, the efficiency scores calculated from the original data are used to form pseudo data. The efficiency measures are input-based measures, so consequently only the inputs are adjusted in the formation of pseudo data and all original output levels are kept in the pseudo data set. Each pseudo data set is similar to the original data set in the sense that both follow the same distributions of inefficiency, and this assures that the levels of performance presented by the bootstrapping results are within the realm of observed behavior. If a large number of (say, B) pseudo data sets are formed, relative to each resulting pseudo reference technology, the efficiency scores can be calculated and the empirical distribution for the efficiency measures can be constructed from the B efficiency scores. It is worth noting that the standard bootstrap may only be applicable in cases in which the statistics of 
interest are smooth functions of the data. To overcome the shortcoming of the inconsistency of naïve bootstraps when applied to DEA, Simar and Wilson propose the use of a smoothed bootstrap as a resampling method for DEA. By using a smoothing method, which centers on the kernel density estimator, a consistent estimator with the boundary condition on efficiency scores (less than or equal to 1) can be obtained. In constructing the density estimator, the choice of kernel function is rarely crucial and is minor in importance compared with the problem of choosing the bandwidth (Greene 2003, pp. 45356). Given this reason and considering the complexity of calculating the bandwidth, we choose a standard normal kernel density. Based on Simar and Wilson's methodology, the algorithm for the bootstrap of DEA efficiency scores is developed as follows:

(i) Calculate the original DEA efficiency scores $\hat{\theta}_{i}(\mathrm{i}=1, \ldots, \mathrm{k})$ under constant returns to scale (CRS) for each observation by solving equation (1) without the constraint that the sum of $z_{i}$ is 1 .

(ii) Let $\beta_{1}^{*}, \ldots, \beta_{k}^{*}$ be a simple bootstrap sample from $\hat{\theta}_{1}, \ldots, \hat{\theta}_{k}$. Generate a random sample of size $\mathrm{k}$ from the following random generator:

$$
\widetilde{\theta}_{i}^{*}= \begin{cases}\beta_{i}^{*}+h \varepsilon_{i}^{*} & \text { if } \beta_{i}^{*}+h \varepsilon_{i}^{*} \leq 1 \\ 2-\beta_{i}^{*}-h \varepsilon_{i}^{*} & \text { otherwise }\end{cases}
$$

where $h$ is the bandwidth of a standard normal kernel density and $\varepsilon_{i}^{*}$ is a random deviate drawn from the standard normal. This generator takes into account the boundary condition of efficiency scores. And $\widetilde{\theta}_{i}^{*}$ has the following properties:

$$
\begin{aligned}
& E\left(\widetilde{\theta}_{i}^{*} \mid \hat{\theta}_{1}, \ldots \hat{\theta}_{k}\right)=\hat{\mu}, \\
& V\left(\widetilde{\theta}_{i}^{*} \mid \hat{\theta}_{1}, \ldots \hat{\theta}_{k}\right)=\hat{\sigma}_{\hat{\theta}}^{2}+h^{2}
\end{aligned}
$$

where $\hat{\mu}$ and $\hat{\sigma}_{\hat{\theta}}^{2}$ are the sample mean and variance of $\hat{\theta}_{1}, \ldots, \hat{\theta}_{k}$, respectively.

(iii) To improve the properties of the sequence $\hat{\theta}_{1}, \ldots, \hat{\theta}_{k}$, another sequence is generated by computing

$$
\theta_{i}^{*}=\bar{\beta}^{*}+\frac{1}{\sqrt{1+h^{2} / \hat{\sigma}_{\hat{\theta}}^{2}}}\left(\widetilde{\theta}_{i}^{*}-\bar{\beta}^{*}\right)
$$


where $\bar{\beta}^{*}=\frac{1}{k} \sum_{i=1}^{k} \beta_{i}^{*}$ and $\hat{\sigma}_{\hat{\theta}}^{2}=\frac{1}{k-1} \sum_{i=1}^{k}\left(\hat{\theta}_{i}-\overline{\hat{\theta}}\right)^{2}$. The sequence $\theta_{i}^{*}$ has better properties such as

$$
\begin{aligned}
& E\left(\theta_{i}^{*} \mid \hat{\theta}_{1}, \ldots, \hat{\theta}_{k}\right)=\hat{\mu}, \\
& V\left(\theta_{i}^{*} \mid \hat{\theta}_{1}, \ldots, \hat{\theta}_{k}\right)=\hat{\sigma}_{\hat{\theta}}^{2}\left(1+\frac{h^{2}}{k\left(\hat{\sigma}_{\hat{\theta}}^{2}+h^{2}\right)}\right) .
\end{aligned}
$$

These are the smoothed bootstrap steps for generating the sequence of $\theta_{i}^{*}$ from $\hat{\theta}_{i}$.

(iv) Construct a bootstrap pseudo data set $\left(X_{i}^{*}, Y_{i}^{*}\right)$ which consists of the constructed pseudo input level $X_{i}^{*}=\left(\hat{\theta}_{i} / \theta_{i}^{*}\right) X_{i}$ and the original input level $Y_{i}^{*}=Y_{i}$.

(v) Compute the bootstrap estimate $\hat{\theta}_{i}^{*}$ by taking the pseudo data as the reference set. In each bootstrap replication, also calculate pure technical efficiency measures $\lambda_{\mathrm{i}}$ and $\gamma_{\mathrm{i}}$.

(vi) Repeat steps (ii)-(v) 1,000 times.

In step (ii), small values of $h$ give smooth density estimates, which place too much weight near the upper bound 1 ; while large values of $h$ provide oversmooth density estimates with long tails at the left. By using Silverman's rule of thumb, which maximizes the likelihood of a cross-validation function, an optimal value of 0.001483 is obtained for $h$ (see Härdle and Linton 1994, p. 2304). The sequence $\theta_{i}^{*}$ in step (iii) obtained by the smoothed bootstrap has better properties than $\tilde{\theta}_{i}^{*}$ in the sense that the variance of $\theta_{i}^{*}$ is asymptotically correct. In the bootstrap resampling, the pseudo input data are generated from resampled CRS efficiency measures as deviations off the CRS estimate of the input set instead of VRS or NIRS. This resampling approach guarantees that the DGP under the pseudo data generation mechanism is characterized by a scale-efficient technology (Löthgren and Tambour 1999). The number of bootstrap iterations is set at 1,000 to make the variability of the boundaries of the bootstrap confidence intervals acceptably low (Efron and Tibshirani 1993, p. 275). 
As Kim and Schmidt (2000) point out, interval estimation of efficiency is often more appropriate from both an academic and policy perspective. The percentile method is used to construct confidence intervals. The percentile method would simply select the appropriate percentiles from the bootstrap distribution. For example, the 90 percent confidence interval for an estimate is constructed by ranking the bootstrapped estimates and then selecting the 50th (5 percent of total iterations) outcome as the lower critical value and the 950th (95 percent of total iterations) outcome as the upper critical value. Based on bootstrap confidence intervals, we can do a hypothesis test on estimates. If the bootstrapped confidence interval for an estimate contains zero, then the null hypothesis that the estimate is not significant from zero cannot be rejected; otherwise, the null hypothesis will be rejected. For a one-sided hypothesis test at the 90 percent confidence level, if the 900th outcome (upper critical value) is less than one, then the null hypothesis that the estimate is equal to one will be rejected and we can conclude that the estimate is less than one at the 90 percent confidence level.

\section{Data}

RCCs' business is much simpler than that of commercial banks. Since RCCs' main business is borrowing from fund deposits and lending to others, deposits are treated as inputs and loans are treated as outputs (Chen 2001). The outputs for RCCs are capital loans to TVEs (township and village enterprises), fixed asset loans to TVEs, agricultural loans, other loans, and deposits to other banks. The outputs are based on the RCCs' balance sheet of credit funds. Capital loans to TVEs are restricted to be used as operating cash, inventory, and short-term investment; and fixed asset loans are loans restricted to buying or constructing fixed assets. Agricultural loans are loans to rural communities or individual farmers that are used for buying machinery, fertilizer, or other production materials. Other loans refer to non-agriculture related loans not in the first three categories and include loans to industry or business. Different loans may have different interest rates set by the government to support some specific types of production during the study period. The inputs for RCCs are specified as total fixed deposits, total current deposits, and employees. Total assets are mostly composed of loans having fixed assets typically accounting for less than 2 percent. For this reason and because of data issues, fixed assets 
were not included as an input. This is understandable when looking at the RCCs' small operating space in rural China.

Our analysis is based on province-level data. Although each RCC in China is an independent entity or accounting unit, because Chinese RCCs' business establishments are based on administrative areas and are currently being reformed and reconstructed by provinces, the aggregated data at the provincial level fit the scenario. In fact, there are quite a few studies based on aggregated state- or national-level data. For example, Armah, Park, and Lovell (1999) use state-level data to measure the impact of state characteristics as key determinants of bank efficiency; Berger, Kashyap, and Scalise (1995) use aggregated national commercial bank data to undertake simulations which suggest nationwide banking will lead to substantial consolidation of the banking industry; Wallace (1994) uses state-level data to analyze structural and efficiency changes in financial performance across agricultural and nonagricultural banks; and Swamy et al. (1996) use state-level commercial bank data to investigate the determinants of U.S. commercial bank performance.

The sample includes 29 out of 31 provinces and regions of mainland China (Figure 3) in years ranging from 1991 to $1995 .^{2}$ Since Chongqing became a central governmentadministered municipality in 1997, it is included as a part of Sichuan province. Tibet is not included because data were unavailable. There are a total of 145 observations. The source of the data is the China Rural Finance Almanac (Agricultural Bank of China, various) for the respective years. The data is summarized in Table 1.

\section{Empirical Results}

The bootstrap results of pure technical efficiency for 29 provinces from 1991 to 1995 with 1,000 iterations and 0.001483 as the bandwidth are shown in Table 2 . The results listed include the medians and confidence intervals at a 90 percent confidence level. The medians are listed instead of the means because the medians provide a more robust measure of location than do the means when distributions are skewed as they are with DEA efficiency scores (Simar and Wilson 1998). Because of small variations in bootstrapping estimates that result from a good DGP and a small bandwidth, we apply the percentile 


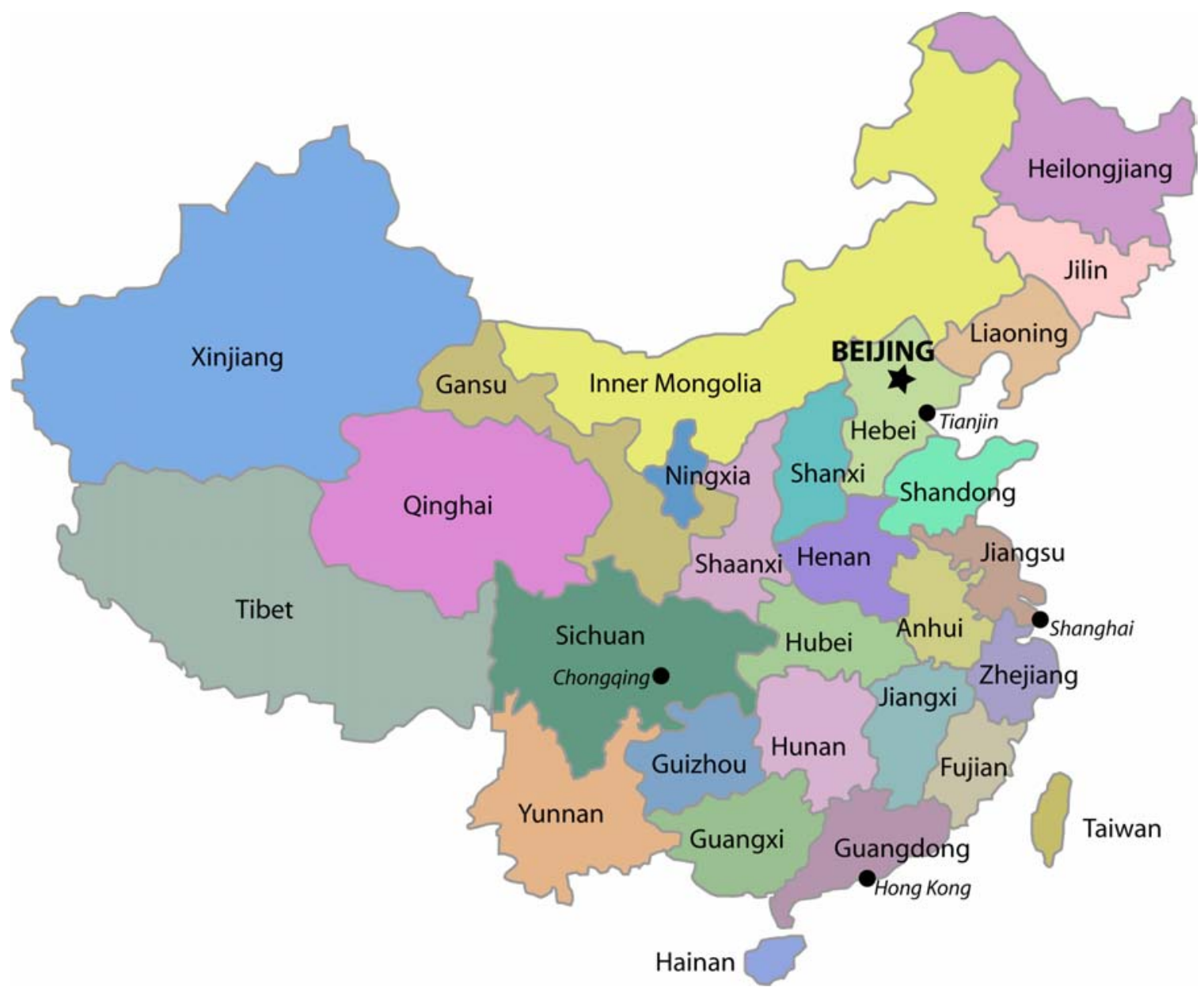

\section{Figure 3. Map of China}

method instead of the complicated bias-corrected percentile acceleration interval introduced by Efron (1987).

Using the percentile method, we can conclude that 16 out of 29 provinces or cities, namely Beijing, Tianjin, Hebei, Heilongjiang, Shanghai, Jiangsu, Zhejiang, Shandong, Henan, Guangdong, Guangxi, Hainan, Shaanxi, Qinghai, Ningxia, and Xinjiang, were technically efficient in every year. ${ }^{3}$ This indicates that the RCCs in those provinces or cities adopted virtually the same practices. They were operating on the relative production frontier. In the meantime, Jiangxi and Hubei were technically inefficient in the first four years while Fujian and Gansu had pure technical inefficiency in the last four years. Anhui, Guizhou, and Yunnan were pure technically efficient in four years, but efficiency occurred in different years. Moreover, Neimenggu, Hunan, and Sichuan were pure tech- 
Technical and Scale Efficiencies for Chinese Rural Credit Cooperatives / 15

TABLE 1. Summary statistics of sample rural credit cooperatives, 1991-1995

\begin{tabular}{|c|c|c|c|c|}
\hline Variable & Minimum & Maximum & Average & $\begin{array}{l}\text { Standard } \\
\text { Deviation }\end{array}$ \\
\hline Y1-Capital loan to TVEs $(¥ 0,000)$ & 1,331 & $5,458,025$ & 532,811 & 791,297 \\
\hline $\begin{array}{l}\text { Y2-Fixed asset loans to } \\
\text { TVEs }(¥ 0,000)\end{array}$ & 487 & $1,108,669$ & 92,277 & 159,501 \\
\hline Y3-Agricultural loans $(¥ 0,000)$ & 8,263 & $1,413,026$ & 298,592 & 282,542 \\
\hline Y4-Other loans $(¥ 0,000)$ & 25 & $2,940,653$ & 239,229 & 425,192 \\
\hline Y5-Deposits to other banks $(¥ 0,000)$ & 0 & $2,097,719$ & 444,987 & 413,737 \\
\hline X1-Fixed deposits $(¥ 0,000)$ & 16,268 & $7,333,675$ & $1,103,862$ & $1,213,853$ \\
\hline X2-Curent deposits $(¥ 0,000)$ & 13,436 & $4,792,190$ & 504,426 & 716,655 \\
\hline X3-Number of employees & 1,433 & 54,900 & 19,328 & 13,330 \\
\hline N-observation number & 145 & & & \\
\hline
\end{tabular}

nically inefficient in three years, while Shanxi, Liaoning, and Jilin were pure technically inefficient in two years.

Table 3 shows the results of overall technical efficiency for 29 provinces from 1991 to 1995 . The results listed also include the medians and confidence intervals at a 90 percent confidence level. Hubei and Yunnan were overall technically inefficient while ten other provinces or cities (Beijing, Tianjin, Hebei, Heilongjiang, Shanghai, Hainan, Shaanxi, Qinghai, Ningxia and Xinjiang) were overall technically efficient in all five years. Fujian, Jiangxi, Hunan, and Gansu had overall technical inefficiency in four years. Jiangsu, Zhejiang, Anhui, Shandong, Henan, Hubei, Hunan, Guangdong, Guangxi, and Yunnan appeared to be overall technical inefficient in more years than to be pure technical inefficient. This results from scale inefficiency.

Table 4 shows the results of scale efficiency measures for 29 provinces from year 1991 to year 1995. The median and confidence intervals at a 90 percent level are listed. Ten provinces or cities (Beijing, Tianjin, Hebei, Heilongjiang, Shanghai, Hainan, Shaanxi, Qinghai, Ningxia, and Xinjiang ) were always scale efficient, while Yunnan was 
TABLe 2. Pure technical efficiency, 1991-1995

\begin{tabular}{|c|c|c|c|c|c|}
\hline Province/City & 1991 & 1992 & 1993 & 1994 & 1995 \\
\hline Beijing & $1(1,1)$ & $1(1,1)$ & $1(1,1)$ & $1(1,1)$ & $1(1,1)$ \\
\hline Tianjin & $1(1,1)$ & $1(1,1)$ & $1(1,1)$ & $1(1,1)$ & $1(1,1)$ \\
\hline Hebei & $1(1,1)$ & $1(1,1)$ & $1(1,1)$ & $1(1,1)$ & $1(1,1)$ \\
\hline Shanxi & $1(1,1)$ & $1(1,1)$ & $0.9956(0.9934,0.9979)$ & $0.9969(0.9947,0.9991)$ & $1(1,1)$ \\
\hline Neimenggu & $1(1,1)$ & $0.9995(0.9975,1)$ & $0.9875(0.9852,0.9898)$ & $0.9904(0.9881,0.9927)$ & $0.9967(0.9943,0.9988)$ \\
\hline Liaoning & $0.9972(0.9949,0.9990)$ & $0.9979(0.9956,0.9998)$ & $1(1,1)$ & $1(1,1)$ & $1(1,1)$ \\
\hline Jilin & $0.9994(0.9976,1)$ & $0.9999(0.9979,1)$ & $0.9910(0.9888,0.9933)$ & $0.9967(0.9943,0.9988)$ & $1(1,1)$ \\
\hline Heilongjiang & $0.9990(0.9969,1)$ & $1(0.9999,1)$ & $1(1,1)$ & $1(1,1)$ & $1(1,1)$ \\
\hline Shanghai & $1(1,1)$ & $1(1,1)$ & $1(1,1)$ & $1(1,1)$ & $1(1,1)$ \\
\hline Jiangsu & $1(1,1)$ & $1(1,1)$ & $1(1,1)$ & $1(1,1)$ & $1(1,1)$ \\
\hline Zhejiang & $1(1,1)$ & $1(0.9994,1)$ & $1(1,1)$ & $1(1,1)$ & $1(1,1)$ \\
\hline Anhui & $1(1,1)$ & $1(1,1)$ & $0.9909(0.9885,0.9931)$ & $0.9983(0.9960,1)$ & $1(1,1)$ \\
\hline Fujian & $1(1,1)$ & $0.9908(0.9885,0.9933)$ & $0.9934(0.9911,0.9957)$ & $0.9943(0.9919,0.9965)$ & $0.9953(0.9930,0.9976)$ \\
\hline Jiangxi & $0.9922(0.9901,0.9947)$ & $0.9904(0.9881,0.9928)$ & $0.9897(0.9875,0.9921)$ & $0.9938(0.9914,0.9963)$ & $1(0.9997,1)$ \\
\hline Shandong & $1(1,1)$ & $1(1,1)$ & $1(1,1)$ & $1(1,1)$ & $1(1,1)$ \\
\hline Henan & $1(1,1)$ & $1(1,1)$ & $1(1,1)$ & $0.9994(0.9971,1)$ & $1(1,1)$ \\
\hline Hubei & $0.9938(0.9914,0.9962)$ & $0.9854(0.9830,0.9879)$ & $0.9889(0.9866,0.9912)$ & $0.9944(0.9922,0.9966)$ & $1(1,1)$ \\
\hline Hunan & $0.9923(0.9901,0.9947)$ & $0.9911(0.9887,0.9932)$ & $0.9952(0.9931,0.9976)$ & $0.9985(0.9961,1)$ & $1(1,1)$ \\
\hline Guangdong & $1(1,1)$ & $1(1,1)$ & $1(1,1)$ & $1(1,1)$ & $1(1,1)$ \\
\hline Guangxi & $1(1,1)$ & $1(1,1)$ & $1(1,1)$ & $1(1,1)$ & $1(1,1)$ \\
\hline Hainan & $1(1,1)$ & $1(1,1)$ & $1(1,1)$ & $1(1,1)$ & $1(1,1)$ \\
\hline Sichuan & $0.9964(0.9938,0.9986)$ & $0.9912(0.9889,0.9936)$ & $0.9970(0.9948,0.9992)$ & $1(1,1)$ & $1(1,1)$ \\
\hline Guizhou & $1(1,1)$ & $1(1,1)$ & $1(1,1)$ & $0.9969(0.9945,0.9992)$ & $1(1,1)$ \\
\hline Yunnan & $1(1,1)$ & $0.9897(0.9875,0.9921)$ & $1(1,1)$ & $0.9987(0.9965,1)$ & $1(1,1)$ \\
\hline Shaanxi & $1(1,1)$ & $1(1,1)$ & $1(1,1)$ & $1(1,1)$ & $1(1,1)$ \\
\hline Gansu & $1(1,1)$ & $0.9963(0.9941,0.9984)$ & $0.9852(0.9828,0.9874)$ & $0.9881(0.9858,0.9904)$ & $0.9925(0.9902,0.9951)$ \\
\hline Qinghai & $1(1,1)$ & $1(1,1)$ & $1(1,1)$ & $1(1,1)$ & $1(1,1)$ \\
\hline Ningxia & $1(1,1)$ & $1(1,1)$ & $1(1,1)$ & $1(1,1)$ & $1(1,1)$ \\
\hline Xinjiang & $1(1,1)$ & $0.9988(0.9967,1)$ & $1(1,1)$ & $1(1,1)$ & $1(1,1)$ \\
\hline
\end{tabular}

Note: The numbers listed are the median with confidence interval at the $90 \%$ level in parentheses. 
TABLE 3. Overall technical efficiency, 1991-1995

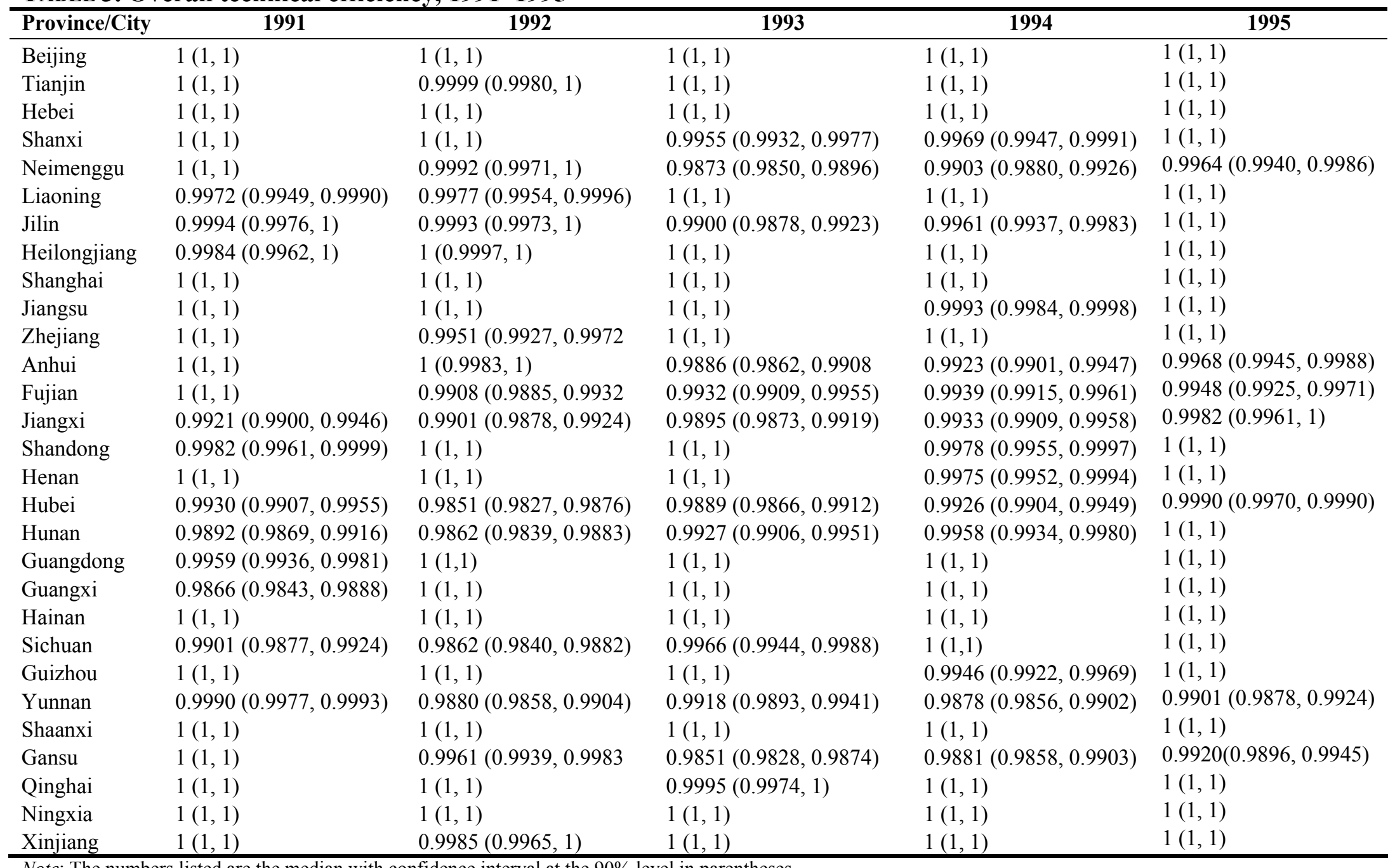


TABLE 4. Scale efficiency, 1991-1995

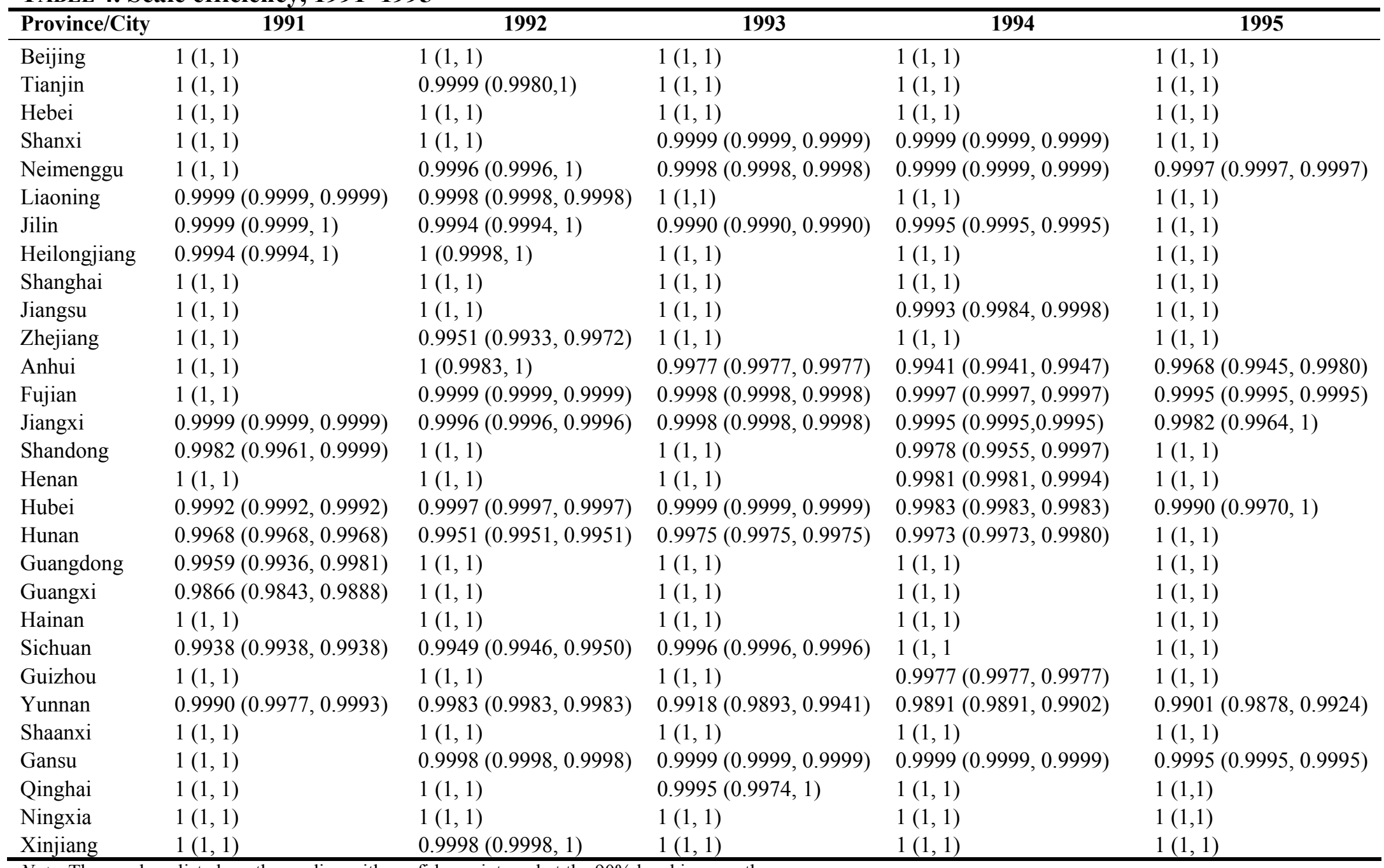

Note: The numbers listed are the median with confidence interval at the $90 \%$ level in parentheses. 
always scale inefficient. Fujian and Gansu were scale inefficient in the last four years while Hubei and Hunan were scale inefficient in the first four years. Neimenggu and Anhui provinces were scale inefficient in the last three years while Sichuan province was scale inefficient in the first three years. Jiangsu, Zhejiang, Henan, Guangdong, Guangxi, and Guizhou provinces were scale inefficient in only one year.

The scale inefficiency is the result of operating at either increasing or decreasing re-

turns to scale. To determine the type of returns to scale, $\hat{\lambda}_{i}$ and $\hat{\gamma}_{i}$ were compared. With 1,000 bootstrap results for each scale inefficiency, if 95 percent or 950 of 1,000 $\hat{\lambda}_{i}$ and $\hat{\gamma}_{i}$ are equal, then decreasing returns to scale exist; if 95 percent or 950 of 1,000 $\hat{\lambda}_{i}$ and $\hat{\gamma}_{i}$ are unequal, then increasing returns to scale exist. Table 5 lists the types of returns to scale for the provinces and cities. Yunnan always had decreasing returns to scale. Hunan had decreasing returns to scale in the first four years and constant returns to scale in the last year while Guangdong, and Guangxi had decreasing returns to scale in the first year and constant returns to scale in the last four years. Jiangsu, Zhejiang, and Henan also had decreasing returns to scale in one year and constant returns to scale in four years but this occurred in different years. Decreasing returns to scale existed in the first three years for Sichuan province and in the last three years for Anhui province. Neimenggu had increasing returns to scale in the last three years. The type of returns to scale for some scale-inefficient provinces varied greatly over time. For example, Jiangxi changed from increasing returns to scale in the first three years to decreasing returns to scale in the fourth year and then to constant returns to scale in the last year; and Fujian changed from constant returns to scale in the first year to decreasing returns to scale in the second year and then to increasing returns to scale in the last three years.

\section{Summary and Conclusions}

In this study, we employed a bootstrap procedure that allows testing of statistical inference of nonparametric scale efficiency measures as well as pure and overall technical efficiency for China's RCCs in individual provinces in different years. This study not only fills the gap in academic research on efficiencies of China's RCCs but also provides insight into guidelines for the current effort to reform and restructure RCCs in China and 
TABLE 5. Returns to scale, 1991-1995

\begin{tabular}{|c|c|c|c|c|c|}
\hline Province & 1991 & 1992 & 1993 & 1994 & 1995 \\
\hline Beijing & $\mathrm{C}$ & $\mathrm{C}$ & $\mathrm{C}$ & $\mathrm{C}$ & $\mathrm{C}$ \\
\hline Tianjin & $\mathrm{C}$ & $\mathrm{C}$ & $\mathrm{C}$ & $\mathrm{C}$ & $\mathrm{C}$ \\
\hline Hebei & $\mathrm{C}$ & $\mathrm{C}$ & $\mathrm{C}$ & $\mathrm{C}$ & $\mathrm{C}$ \\
\hline Shanxi & $\mathrm{C}$ & $\mathrm{C}$ & I & $\mathrm{D}$ & $\mathrm{C}$ \\
\hline Neimenggu & $\mathrm{C}$ & $\mathrm{C}$ & I & I & I \\
\hline Liaoning & $\mathrm{D}$ & I & $\mathrm{C}$ & $\mathrm{C}$ & $\mathrm{C}$ \\
\hline Jilin & $\mathrm{C}$ & $\mathrm{C}$ & I & I & $\mathrm{C}$ \\
\hline Heilongiiang & $\mathrm{C}$ & $\mathrm{C}$ & $\mathrm{C}$ & $\mathrm{C}$ & $\mathrm{C}$ \\
\hline Shanghai & $\mathrm{C}$ & $\mathrm{C}$ & $\mathrm{C}$ & $\mathrm{C}$ & $\mathrm{C}$ \\
\hline Jiangsu & $\mathrm{C}$ & $\mathrm{C}$ & $\mathrm{C}$ & D & $\mathrm{C}$ \\
\hline Zhejiang & $\mathrm{C}$ & $\mathrm{D}$ & $\mathrm{C}$ & $\mathrm{C}$ & $\mathrm{C}$ \\
\hline Anhui & $\mathrm{C}$ & $\mathrm{C}$ & $\mathrm{D}$ & D & $\mathrm{D}$ \\
\hline Fujian & $\mathrm{C}$ & D & I & I & I \\
\hline Jiangxi & I & I & I & D & $\mathrm{C}$ \\
\hline Shandong & $\mathrm{D}$ & $\mathrm{C}$ & $\mathrm{C}$ & $\mathrm{D}$ & $\mathrm{C}$ \\
\hline Henan & $\mathrm{C}$ & $\mathrm{C}$ & $\mathrm{C}$ & $\mathrm{D}$ & $\mathrm{C}$ \\
\hline Hubei & $\mathrm{D}$ & I & I & $\mathrm{D}$ & $\mathrm{C}$ \\
\hline Hunan & $\mathrm{D}$ & D & $\mathrm{D}$ & $\mathrm{D}$ & $\mathrm{C}$ \\
\hline Guangdong & $\mathrm{D}$ & $\mathrm{C}$ & $\mathrm{C}$ & $\mathrm{C}$ & $\mathrm{C}$ \\
\hline Guangxi & $\mathrm{D}$ & $\mathrm{C}$ & $\mathrm{C}$ & $\mathrm{C}$ & $\mathrm{C}$ \\
\hline Hainan & $\mathrm{C}$ & $\mathrm{C}$ & $\mathrm{C}$ & $\mathrm{C}$ & $\mathrm{C}$ \\
\hline Sichuan & D & $\mathrm{D}$ & D & $\mathrm{C}$ & $\mathrm{C}$ \\
\hline Guizhou & $\mathrm{C}$ & $\mathrm{C}$ & $\mathrm{C}$ & I & $\mathrm{C}$ \\
\hline Yunnan & D & $\mathrm{D}$ & D & $\mathrm{D}$ & $\mathrm{D}$ \\
\hline Shaanxi & $\mathrm{C}$ & $\mathrm{C}$ & $\mathrm{C}$ & $\mathrm{C}$ & $\mathrm{C}$ \\
\hline Gansu & $\mathrm{C}$ & I & $\mathrm{D}$ & I & I \\
\hline Qinghai & $\mathrm{C}$ & $\mathrm{C}$ & $\mathrm{C}$ & $\mathrm{C}$ & $\mathrm{C}$ \\
\hline Ningxia & $\mathrm{C}$ & $\mathrm{C}$ & $\mathrm{C}$ & $\mathrm{C}$ & $\mathrm{C}$ \\
\hline Xinjiang & $\mathrm{C}$ & $\mathrm{C}$ & $\mathrm{C}$ & $\mathrm{C}$ & $\mathrm{C}$ \\
\hline
\end{tabular}

Note: C: constant returns to scale; I: increasing returns to scale; D: decreasing returns to scale. 
for future reform in a wider range. Moreover, because the application of the bootstrap to the DEA method is still under development and previous studies are few and recent, this study offers a fresh application of bootstrapping to the DEA method.

The empirical results present important evidence on efficiency in China's RCCs. As the experimental reforms are currently being undertaken in eight provinces and cities, the evidence presented could prove extremely useful. The estimated efficiency results are close to one and to each other, which indicates that RCCs in each province are mandated to take the same technology and practices and engage in similar scales of production. Among the eight experimental provinces or cities, our evidence points to a need for RCCs in Jiangxi province to put more effort into adopting the best practices existing in RCCs to improve their pure technical efficiency, adjusting their scales of loan services to obtain scale efficiency, and, finally, increasing the overall efficiency of the agricultural lending system. Jilin, Jiangsu, Zhejiang, Shandong, and Guizhou provinces also need to focus on adopting best practices or adjusting their scales of loans in order to obtain overall technical efficiency. Shaanxi is the only province of the eight experimental provinces and cities that has both technical efficiency and scale efficiency. However, since the measurement is a relative comparison, it does not mean that RCCs in Shaanxi province have adopted the best practices for financial services outside of RCCs. A next step would be to compare the RCCs with more modern financial services like those in developed countries to possibly improve efficiency.

RCCs, as a micro-foundation of the financial sector, are greatly influenced by the macro-environment set by the government and society. However, in this empirical study, we are concerned only with the internal structure of the RCCs and do not consider the issues of government, financial systems, and other macro issues. Reform of RCCs is quite complicated. It depends not only on self-improvement of RCCs but also involves government policy on reform of their managerial system, their form of ownership, and dealing with past nonperforming loans. In addition, reform cannot come without the government taking steps toward financial market liberalization. Finally, in this study we did not consider the interaction between the non-performing loans and cost efficiency (Berger and DeYoung 1987) because of unavailable data on non-performing loans for each province, which could result in an overestimate of cost efficiency. 


\section{Endnotes}

1. The four state banks have percentages of nonperforming loans between 25 and 40 percent (Pener 2001).

2. After the RCCs' separation from the Agricultural Bank of China in 1996, data on the RCCs are not available in the China Rural Finance Almanac. Given the fact that RCCs have not changed significantly after the separation, the data ranging in this period are still representative.

3. For Heilongjiang in 1991 and 1992, Zhejiang and Xinjiang in 1992, and Henan in 1994, since the 900th of their sorted pure technical efficiency measures is one, we cannot reject the null hypothesis that their pure technical efficiency measures are one relative to the alternative hypothesis that their pure technical efficiency measures are less than one at the 90 percent confidence level. Therefore, we conclude that these provinces were pure technically efficient. We make a similar conclusion for other intervals containing one. 


\section{References}

Agricultural Bank of China. Various. China Rural Finance Almanac.

Aly, H., R. Grabowski, C. Pasurka, and N. Rangan. 1990. "Technical, Scale, and Allocative Efficiencies in U.S. Banking: An Empirical Investigation.” Review of Economics and Statistics 72: 211-18.

Armah, B., T. Park, and K. Lovell. 1999. "Evaluating the Performance of Agricultural Bank Management: The Impact of State Regulatory Policies." Journal of Agricultural and Applied Economics 31(December): 437-48.

Banker, R., A. Charnes, and W. Cooper. 1984. "Some Models for Estimating Technical and Scale Inefficiencies in Data Envelopment Analysis." Management Science 30: 1078-92.

Berger, A., and D. Humphrey. 1997. "Efficiency of Financial Institutions: International Survey and Directions of Future Research." European Journal of Operation Research 98(April): 175-212.

Berger, A., A. Kashyap, and J. Scalise. 1995. "The Transformation of the U.S. Banking Industry: What a Long Strange Trip It's Been.” Brookings Papers on Economic Activity 2: 55-201.

Berger, A., and R. DeYoung. 1997. "Problems Loans and Cost Efficiency in Commercial Banks." Journal of Banking and Finance 21: 849-70.

Chen, T-Y. 2001. “An Estimation of X-inefficiency in Taiwan's Banks.” Applied Financial Economics 11: $237-42$.

Drake, L., and M. Hall. 2003. "Efficiency in Japanese Banking: An Empirical Analysis.” Journal of Banking and Finance 27: 891-917.

Efron, B. 1987. "Better Bootstrap Confidence Intervals." Journal of the American Statistical Association 82: 171-85.

Efron, B., and R. Tibshirani. 1993. An Introduction to the Bootstrap. New York: Chapman and Hall.

Ellinger, P.N. 1994. "Potential Gains from Efficiency Analysis of Agricultural Banks." American Journal of Agricultural Economics 76(August): 652-54.

Fang, X. 2001. "Reconstructing the Micro-Foundation of China's Financial Sector." Paper presented at the Conference on Financial Sector Reform in China, Harvard University, Cambridge, MA, September 1113. http://www.ksg.harvard.edu/cbg/Conferences/financial_sector/ReconstructingtheMicroFoundation.pdf (accessed July 2004).

Färe, R., S. Grosskopf, and C. Lovell. 1985. The Measurement of Efficiency of Production. Boston: Kluwer-Nijhoff Publishing.

Farrell, M. 1957. "The Measurement of Productive Efficiency." Journal of the Royal Statistical Society, Series A, General, 120: 253-81. 
Featherstone, A.M., and C. B.Moss. 1994. "Measuring Economies of Scale and Scope in Agricultural Banking." American Journal of Agricultural Economics 76(August): 655-61.

Greene, W. 2003. Econometric Analysis. New Jersey: Pearson Education, Inc.

Han, J. 2003. "Propel All-Round Agricultural Financial Reform.” China Economy Times, June 9.

- n.d. "Scarcity of Agricultural Capital Is Becoming a Big Obstacle to Agricultural Development." http://www.agrisd.gov.cn/info/archive/38248.shtml (accessed November 13).

Härdle, W., and O. Linton. 1994. “Applied Nonparametric Methods.” In Handbook of Econometrics, vol. 4. Edited by R. Engle and D. Mcfadden. Amsterdam: Elsevier.

Kim, Y., and P. Schmidt. 2000. "A Review and Empirical Comparison of Bayesian and Classical Approaches to Inference on Efficiency Levels in Stochastic Frontier Models with Panel Data." Journal of Productivity Analysis 14: 91-118.

Löthgren, M., and M. Tambour. 1999. "Testing Scale Efficiency in DEA Models: A Bootstrapping Approach." Applied Economics 31: 1231-37.

Mu, R. 2003. "Reflection on the Reform of Rural Credit Cooperatives." People's Daily, September 17.

Pener, A.M. 2001. "Capital Markets Transparency and Security: The Nexus between U.S.-China Security Relations and America's Capital Markets." U.S.-China Economic and Security Review Commission Research Paper, June.

Rangan, N., Y. Hassan, C. Pasurka, and R. Grabowski. 1988. "The Technical Efficiency of U.S. Banks." Economic Letters 28: 169-75.

Simar, L., and P. Wilson. 1998. "Sensitivity Analysis of Efficiency Scores: How to Bootstrap in Nonparametric Frontier Models.” Management Science 44: 49-61.

Swamy, P., J. Barth, R. Chou, and J. Jahera. 1996. "Determinants of U.S. Commercial Bank Performance: Regulatory and Econometric Issues." Research in Finance 14: 117-56.

Wallace, G. 1994. "Agricultural and Nonagricultural Banking Statistics.” U.S. Department of Agriculture, Economic Research Service, Statistical Bulletin No. 883, Washington, D.C.

Wen, T. 2001. "Farmer's Credit and People-to People Loan.” http://www1.cei.gov.cn/ forum50/doc/50cyfx/200107311731.htm (accessed November 2003).

Xie, P. 2001. "Disputes on the System Reform of China Rural Credit Cooperatives." Financial Studies 1: $1-12$.

. 2003. "Reforms of China's Rural Credit Cooperatives and Policy Options." China Economic Review 14: 434-42.

Zuo, X. 2001. "The Development of Credit Unions in China: Past Experiences and Lessons for the Future." Paper presented at "Financial Sector Reform in China." Paper presented at the Conference on Financial Sector Reform in China, Harvard University, Cambridge, MA, September 11-13. http://www.ksg. harvard.edu/cbg/Conferences/financial_sector/PastFailuresoftheCreditUnion.pdf (accessed November 2003). 